\title{
An Analysis of the Cultivation of Service Awareness of the Tourism Vocational Education in Japan
}

\author{
Yin Juan \\ Zhou Youguang School of Languages and Cultures, Changzhou University, Jiangsu Province P.R.C., \\ 1 Gehe Leke Road, Science and Education Town, Changzhou \\ e-mail: isable@cczu.edu.cn
}

\begin{abstract}
Through examining the curriculum installation in the tourism vocational colleges in Japan, teachers and students' awareness of the service and service consciousness cultivation, this paper analyzes the advantages of the vocational colleges of the cultivation of service awareness in Japan, and proposes the corresponding suggestions and countermeasures for the shortcomings in China.
\end{abstract}

Keywords- Japan; tourism; vocational education; cultivation of service awareness; analysis

\section{INTRODUCTION}

\subsection{Research background}

The service awareness refers to the service industry participants' knowledge and understanding of the service, feelings and cultivation of the service within the inherent quality, and awareness to provide the paid work for others and the society consciously, actively and heartfeltly. It includes the service understanding, service feeling and service behavioral pattern. The service industry participants' service awareness is one of the key factors directly influencing the service quality and consumers' satisfaction, and the importance is stressed by the previous researches in the tourism field. However, the discussion on the teachers and students' basic understanding of the service in the researches on vocational education in our country insufficient. In addition to the curriculum installation, the teachers and students' understanding of the service and service awareness is a key factor influencing the cultivation of service awareness. The service level in Japan is highly developed, the Japanese people have a strong service awareness, and this is inseparable with the cultivation of service awareness. Starting from the major of hotel management in the tourism vocational education, the paper makes an empirical study of the curriculum installation in the representative tourism vocational colleges in Japan, teachers and students' service awareness, and proposes the corresponding suggestions on the development in our country.

\subsection{Current situation in Japan}

Japan's vocational education began in the early Meiji, and the biggest favorable turn originated from the specialized school system founded in 1975. The specialized school can be divided into three kinds according to different admission qualifications- specialized school, higher specialized school and general specialized school. The specialized school in parallel with the university and short-term university achieved the rapid development. With the main enrollment target of high school graduates, the educational system in the specialized school is 2-4 years equal to the junior college in our country. As "the higher educational institution in the third level", it is a typical representative of higher education, and plays a decisive role.

\subsection{Research method}

With the sociological interview survey and the empirical study object of the teachers and students majored in the management of HTO, two-year tourism specialized school which is a representative tourism vocational college in Japan, the paper analyzes the curriculum installation, teachers and students' recognition of the service and service awareness cultivation. There are three contents in the interviewteachers and students' understanding of the service and service awareness, teachers' teaching practice and students' recognition of the service education, teachers and students' recognition of the current status of the cultivation of the service awareness in the school.

\section{CULTIVATION OF SERVICE AWARENESS}

2.1 Curriculum installation

HTO tourism school is equal to the junior college in our country, there are 7 majors and over 1000 students at present. There are 11 teachers in the hotel management major and 11 objects implementing the actual interview accounting for $100 \%$ of the total number. There are 215 students in the first and second grades, and 34 objects implementing the actual interview accounting for $16 \%$ of the total number. The curriculum installation of HTO hotel can be divided into four sections- compulsory course, optional course, various activities and special subject. 'Compulsory course' includes 8 common courses of business etiquette, reception skill, 11 professional courses of accommodation practice and business English. In the 'optional course', 3 courses shall be selected among 20 courses of reception psychology and service assistant. In the professional courses, 2 sets shall be selected among 19 sets of courses of bartender course and tour guide business course. The related theory and practical operation course are set in each set of the course. 
Moreover, there are more foreign-language courses in the curriculum installation. In addition to the main English courses, Chinese, Korean, French, sign language and other foreign-language courses are opened. The business etiquette, service etiquette and multiple subjects related with the etiquette are established.

2.2 Teachers' cognition on the service and the service awareness cultivation

Concerning the understanding of the 'service' and 'service awareness', the teachers in HTO distinguish from the business interests, and hold that the service can be regarded as the goods to exchange for money when satisfying the guests, while the service awareness refers to the mind to care for others which can not be measured by money. In the teaching practice, in addition to the lectures in class, HTO teachers stress on infusing the meaning of the service awareness through individual word and deed, and note to combine the teaching and own behavior. This echoes the teachers' understanding of the present status on the cultivation of the service awareness in the school. On the other hand, HTO teachers hold that the school should open the multiple-service guiding-related courses to help students understand and experience the services combined with teachers' exemplary role on the basis. That the school shall focus on the moral etiquette education in the daily behavior specification and try to create the campus atmosphere noting the service awareness is affirmed.

2.3 Students' cognition on the service and service awareness cultivation

Concerning the understanding of 'service' and 'service awareness', most students hold that the service is a kind of profession and commodity meeting the guests' demands, while the service awareness is interpreted from the specific forms of "smile, consider for the other parties standing on the other's position". We can know that no matter the services or the service awareness, students tend to give shape to the intangible contents, and understand the abstract concepts through the specific forms. In addition, a large part of students answer 'through teachers' words and deeds and various activities held in the school', this can show that teachers' words and deeds and the activities held in the school play an important role to help students understand and experience the service and service awareness, and it is fruitful in the cultivation of own service awareness and the evaluation of school education.

\subsection{Features of service awareness cultivation in Japan}

(1) In Japan, the curriculum installation is oriented with the market demands, and it implements the thorough applied education and practical education.

(2) The schools and teachers in Japan pay attention to the cultivation of students' etiquette habits, stress the students' demonstration effects, and open the targeted service-guiding courses.
(3) Most teachers in the vocational colleges in Japan are experienced insiders.

\section{CONCLUSIONS}

According to the empirical research and analysis results in the service awareness cultivation in the higher vocational education in Japan, the following measures shall be adopted to improve the service awareness cultivation ability in our country:

\subsection{Curriculum installation}

The practical courses related with the service shall be added in the reform of curriculum installation. In order to cultivate the applied talent meeting the practical demands, the amount and types of professional subjects shall be expanded to seek the diversified forms and enriched contents.

\subsection{Adjustment of the teacher structure}

Influenced by the educational system and other factors, the teacher talents introduced in the higher vocational education in our country focus on the major and educational backgrounds, and the industrial experience is ignored. Therefore, there are fewer teachers with enriched industrial experience among the teachers. Although the double teachers are cultivated through the temporary enterprise, the insiders with profound qualification are different from the talents graduated from colleges. Therefore, the higher vocational education shall study the practice in Japan, hire more industrial talents, pay attention to the teachers' active role, and discuss to establish the diversified teacher evaluation system.

\subsection{Improvement of teachers' ability}

Supervise the teachers to know own deficiencies, try to improve own service awareness and expertise, and construct the reasonable and feasible service awareness cultivation mode combined with the national conditions and education system in China from the daily teaching.

\section{REFERENCES}

[1] Li Xiaodong. On the cultivation of tourism service awareness in the higher vocational education [J]. Chinese High-Tech Enterprise, 2009 (19): 186-188.

[2] Zhou Lijun, Wu Anping, Yang Xufei. Analysis on the cultivation of service awareness for the students majored in the tourism [J]. Journal of Changchun University, 2009, 19(5): 88-89,92.

[3] Li Yuezheng. Comparative study on the undergraduate curriculum system majored in the tourism between China and Japan [D]. Liaoning Normal University, 2008.

[4] Song Deli. Problem and solutions for the development of tourism vocational education [J]. Tourism Science, 2012, 26(2): 85-94. 
[5] Li Defang. Comparison on the development status of higher vocational technology education in China and Japan [J]. Journal of Jiangsu Teachers University of Technology, 2005, 11(1): 16-19.

[6] Yin Juan. Comparative study on the service awareness [M]. Nanjing: Nanjing University Press, 2012. 